\title{
Commentary: Moderate ischemic mitral regurgitation: Which cases benefit most from isolated coronary artery bypass?
}

\author{
Daniel J. P. Burns, MD, MPhil
}

From the Department of Thoracic and Cardiovascular Surgery, Cleveland Clinic Foundation, Cleveland, Ohio. Disclosures: Author has nothing to disclose with regard to commercial support.

Received for publication Sept 25, 2018; accepted for publication Sept 26, 2018; available ahead of print Nov 1, 2018.

Address for reprints: Daniel J. P. Burns, MD, MPhil, Cleveland Clinic, 9500 Euclid Ave, J4-133, Cleveland, OH 44195 (E-mail: burnsd@ccf.org).

J Thorac Cardiovasc Surg 2019;157:1808

$0022-5223 / \$ 36.00$

Copyright (c) 2018 by The American Association for Thoracic Surgery

https://doi.org/10.1016/j.jtcvs.2018.09.074

In patients with ischemic mitral regurgitation (MR), MR resolution may not predictably or consistently occur after revascularization alone. As such, it becomes tempting to embark on a more complicated and challenging procedure for the sake of treating the mitral valve. This must be balanced against the risk of complicating the procedure, potentially putting the patient at increased risk. The success and durability of repair is questionable, as ischemic mitral regurgitation is, at its foundation, a ventricular problem.

A recent randomized trial addressed this very issue. With mitral repair at the time of coronary artery bypass (CABG), Michler and colleagues ${ }^{1}$ demonstrated a more durable correction of moderate ischemic MR at 2 years. However, this failed to translate into a concomitant benefit for parameters of left ventricular reverse remodeling, survival, adverse events, or readmissions over the same follow-up period, compared with CABG alone. Quality-of-life results were inconsistent, with 3 of 4 scales demonstrating no difference between groups.

To help answer the question of how to best address ischemic MR, Sun and colleagues ${ }^{2}$ have endeavored to describe anatomical variables that predict improvement in ischemic MR when treated by isolated off-pump CABG. This singlecenter prospective cohort study involved 143 selected patients. Preoperative transthoracic echocardiography was performed 1 week before surgery and analyzed according to several anatomic parameters. This was repeated at 1 year, with patients considered "improved" if they demonstrated absent or mild MR or "failure" if MR was moderate or severe.

Independent predictors of MR improvement were analyzed by multivariable logistic regression, including the following echocardiographic parameters: nonplanar angle, ejection fraction, and tethering angles of P1 to P3 as well as A3. P3 tethering angle (odds ratio [OR], 0.697; $95 \%$ confidence interval, $0.602-0.807)$ and nonplanar angle (OR, 0.769; 95\% confidence interval, 0.679-0.870) emerged as independent predictors of MR improvement.

These results suggest that in selected patients, it is reasonable to perform isolated $\mathrm{CABG}$ to address both coronary disease and ischemic MR. However, the limitations of this study must also be understood. This is a small study

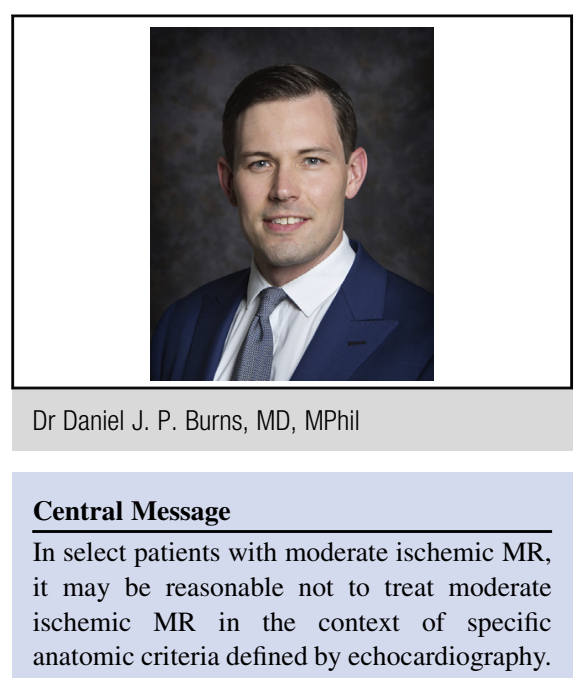

See Article page 1795 .

from a single center and, therefore, may not be generalizable. Eight patients died during follow-up, potentially contributing to a differential effect in a small sample. The OR for improvement in MR is based on a 1-degree change in angle and therefore calls into question the ability of typical transthoracic echocardiography to accurately assess subtle changes, as well as interpretability of the risk in meaningful terms to the patient. Finally, and arguably most importantly, this study does not include an assessment of myocardial viability, potentially crucial to ventricular recovery and ultimate MR improvement.

Ultimately, this study demonstrates that in select cases, it may be reasonable to leave the valve alone when faced with moderate ischemic MR. The parameters highlighted may help select which patient is a better fit for isolated CABG. Just as there are many parameters associated with recurrent MR following repair for ischemic MR, ${ }^{3}$ there may ultimately be an increasing number of parameters associated with MR improvement in the absence of a formal mitral repair.

\section{References}

1. Michler RE, Smith PK, Parides MK, Ailawadi G, Thourani V, Moskowitz AJ, et al. Two-year outcomes of surgical treatment of moderate ischemic mitral regurgitation. N Engl J Med. 2016;374:1932-41.

2. Sun X, Jiang Y, Huang G, Huang J, Shi M, Pang L, et al. Three-dimensional mitral valve structure in predicting moderate ischemic mitral regurgitation improvement after coronary artery bypass grafting. J Thorac Cardiovasc Surg. 2019;157: 1795-803.e2.

3. Crestanello JA. Surgical approach to mitral regurgitation in chronic heart failure: when is it an option? Curr Heart Fail Rep. 2012;9:40-50. 